
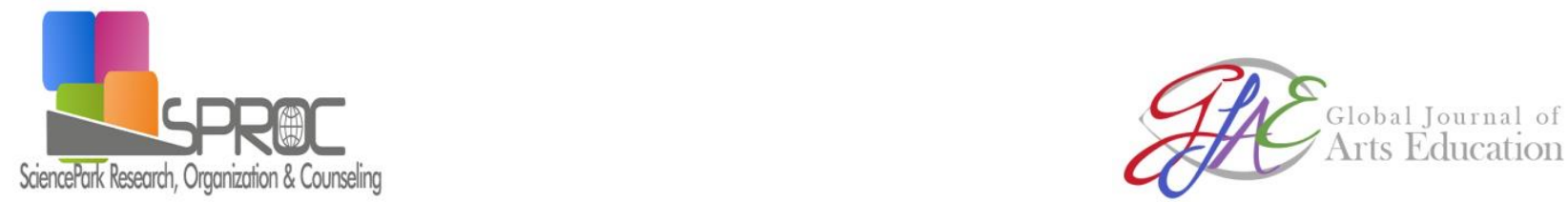

www.gjae.eu

\title{
The roles of art educationalists to realize the aims of the art education: Bauhaus case
}

Tamer Kavuran ${ }^{*}$

Bayram Dede

Suggested Citation:

$E$ stf Est Esff tE fb rst $E$

Abstract 


\section{Introduction}

2. Method

3. The educators and their features who contributed to art education at Bauhaus Johannes Itten's preparatory education class 
fb nst $E$

$\underset{E}{f}$ st Ef fb rst $E \cap \quad P$ tt sE st st $S \quad E$

$\underset{E}{f}$ st Ef fb nt $E$ n Esttfff ffittte fi fi $E$ 
$f b$ ist $E$

E stf Est ESff tE

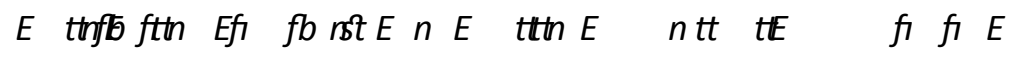


$f b$ rst $E$

$E \quad$ thfo fth Efi fb nst $E \cap E$ E fifite $\quad$ fi fi $\quad E$ 
4. Conclusion and Recommendations

References

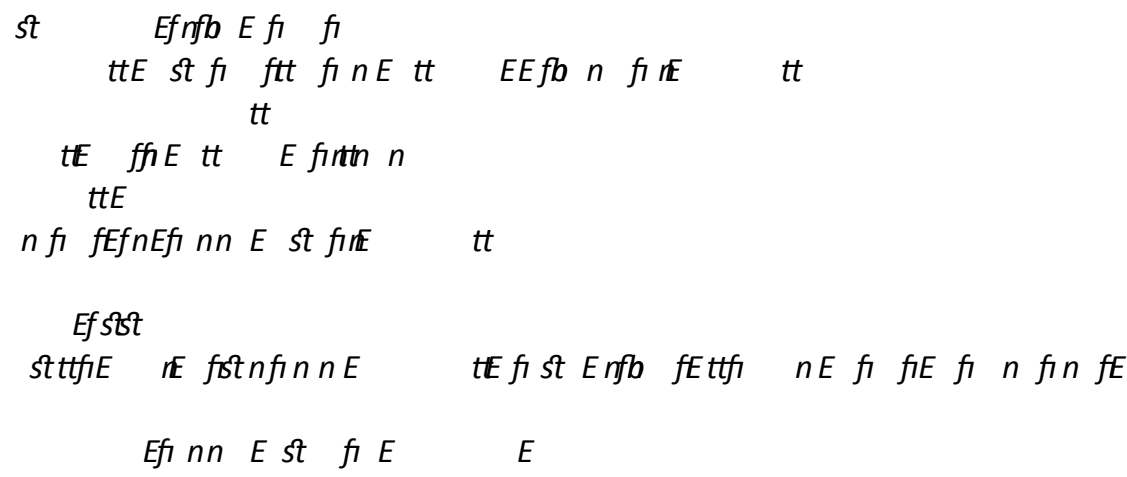


$f b$ rst $E$

$$
f E \text { tEESff } n \text { ftt fifbfbite fEE tUE } E \text { ftth } E \text { fist }
$$

$f E \quad t E f i t t f t t t i$

fi $f i E$ tt 